\title{
Epidemiological and entomological studies of malaria transmission in Tibati, Adamawa region of Cameroon 6 years following the introduction of long-lasting insecticide nets
}

Lionel Brice Feufack-Donfack ${ }^{1,2+}$, Elangwe Milo Sarah-Matio ${ }^{1,3+}$, Luc Marcel Abate ${ }^{3}$, Aline Gaelle Bouopda Tuedom ${ }^{1,8}$, Albert Ngano Bayibéki ${ }^{4}$, Christelle Maffo Ngou ${ }^{1,3}$, Jean-Claude Toto ${ }^{5}$, Maurice Marcel Sandeu ${ }^{6,7}$, Carole Else Eboumbou Moukoko ${ }^{1,8}$, Lawrence Ayong ${ }^{1}$, Parfait Awono-Ambene ${ }^{5}$, Isabelle Morlais ${ }^{1,3}$ and Sandrine Eveline Nsango ${ }^{1,8^{*}}$

\begin{abstract}
Background: Malaria remains a serious public health problem in Cameroon. Implementation of control interventions requires prior knowledge of the local epidemiological situation. Here we report the results of epidemiological and entomological surveys carried out in Tibati, Adamawa Region, Cameroon, an area where malaria transmission is seasonal, 6 years after the introduction of long-lasting insecticidal bed nets.

Methods: Cross-sectional studies were carried out in July 2015 and 2017 in Tibati. Thick blood smears and dried blood spots were collected from asymptomatic and symptomatic individuals in the community and at health centers, respectively, and used for the molecular diagnosis of Plasmodium species. Adult mosquitoes were collected by indoor residual spraying and identified morphologically and molecularly. The infection status of Plasmodium spp. was determined by quantitative PCR, and positivity of PCR-positive samples was confirmed by Sanger sequencing.

Results: Overall malaria prevalence in our study population was 55.0\% (752/1367) and Plasmodium falciparum was the most prevalent parasite species (94.3\%), followed by P. malariae (17.7\%) and P. ovale (0.8\%); 92 (12.7\%) infections were mixed infections. Infection parameters varied according to clinical status (symptomatic/asymptomatic) and age of the sampled population and the collection sites. Infection prevalence was higher in asymptomatic carriers (60.8\%), but asexual and sexual parasite densities were lower. Prevalence and intensity of infection decreased with age in both the symptomatic and asymptomatic groups. Heterogeneity in infections was observed at the neighborhood level, revealing hotspots of transmission. Among the 592 Anopheles mosquitoes collected, 212 (35.8\%) were An. gambiae, 172 (29.1\%) were An. coluzzii and 208 (35.1\%) were An. funestus (s.s.). A total of 26 (4.39\%) mosquito specimens were infected by Plasmodium sp. and the three Anopheles mosquitoes transmitted Plasmodium at equal efficiency.
\end{abstract}

\footnotetext{
*Correspondence: nsango2013@yahoo.fr; nsango@pasteur-yaounde.org

†Lionel Brice Feufack-Donfack and Elangwe Milo Sarah-Matio contributed equally to this work

1 Service de Paludisme du Centre Pasteur Cameroun, BP 1274, Yaounde, Cameroon

Full list of author information is available at the end of the article
}

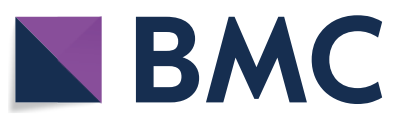

(c) The Author(s) 2021. Open Access This article is licensed under a Creative Commons Attribution 4.0 International License, which permits use, sharing, adaptation, distribution and reproduction in any medium or format, as long as you give appropriate credit to the original author(s) and the source, provide a link to the Creative Commons licence, and indicate if changes were made. The images or other third party material in this article are included in the article's Creative Commons licence, unless indicated otherwise in a credit line to the material. If material is not included in the article's Creative Commons licence and your intended use is not permitted by statutory regulation or exceeds the permitted use, you will need to obtain permission directly from the copyright holder. To view a copy of this licence, visit http://creativecommons.org/licenses/by/4.0/. The Creative Commons Public Domain Dedication waiver (http://creativeco mmons.org/publicdomain/zero/1.0/) applies to the data made available in this article, unless otherwise stated in a credit line to the data. 
Surprisingly, we found an An. coluzzii specimen infected by Plasmodium vivax, which confirms circulation of this species in Cameroon. The positivity of all 26 PCR-positive Plasmodium-infected mosquitoes was successively confirmed by sequencing analysis.

Conclusion: Our study presents the baseline malaria parasite burden in Tibati, Adamawa Region, Cameroon. Our results highlight the high malaria endemicity in the area, and hotspots of disease transmission are identified. Parasitological indices suggest low bednet usage and that implementation of control interventions in the area is needed to reduce malaria burden. We also report for the first time a mosquito vector with naturally acquired $P$. vivax infection in Cameroon.

Keywords: Malaria, Plasmodium vivax, Anopheles coluzzii, Epidemiology, Entomology, Cameroon

\section{Background}

Malaria remains a deadly scourge in many parts of the world, with 409,000 deaths from this disease reported globally in 2019. Over the past 10 years, a declining trend has been observed in the global incidence of cases and deaths due to malaria, 57 and $10 \%$, respectively [1]. Disease control efforts rely at least in part on vector control measures, in particular the use of long-lasting insecticidal-treated bed nets (LLINs) and indoor residual spraying (IRS). Many countries are now adopting elimination strategies as part of their malaria operational plans, even if malaria burden has remained unchanged in some countries in sub-Saharan Africa. Unfortunately, the African region continues to account for over $90 \%$ of all malaria deaths [1].

In Cameroon, malaria remains a serious public health problem. Transmission is heterogeneous across the country, ranging from perennial transmission in the southern forested regions to seasonal and unstable transmission in the northern Sudano-savannah and Sahelian regions. Of the 52 formally recognized Anopheles species present in Cameroon, only 16 are able to transmit the disease to humans [2-4], and the most common and efficient vector species are Anopheles gambiae, An. coluzzii, An. arabiensis, An. funestus, An. nili and An. moucheti [5, 6]. Over the past 9 years there has been significant progress in terms of malaria control and prevention. Indeed, from 2010 to 2019 , the morbidity and mortality due to malaria decreased from 36 to $28 \%$ and from 31 to $18.3 \%$, respectively; however, the situation is not yet under control as the whole country is still at risk of disease transmission $[7,8]$. These observed reductions are due to the efforts of the Government of Cameroon and international partners, with a heavy reliance on mass distribution campaigns of LLINs and the use of sulfadoxine/pyrimethamine either alone for intermittent preventive treatment in pregnant women or in combination with amodiaquine for seasonal malaria chemoprevention in children aged $<5$ years. The introduction of artemisinin-based combination therapies (ACTs) for the treatment of uncomplicated malaria and of free healthcare management of severe malaria cases in children aged $<5$ years have also contributed to malaria reduction [8].

Nevertheless, the effectiveness of control measures is threatened by the rapid expansion of insecticide resistance in vector populations [9-13], changes in vector host-seeking, biting and resting behaviors $[14,15]$, the emergence and rapid spread of drug-resistant parasite strains [16-20] and the diversity of the vectorial system [2] and parasite species [21, 22]. In Cameroon, four Plasmodium species are known at the present time to cause malaria, among which $P$. falciparum is considered to be the most prevalent and virulent parasite, responsible for $82-100 \%$ of all malaria cases depending on the locality [23-26]. Other human-infecting Plasmodium are also present in Cameroon, including $P$. malariae, $P$. ovale and $P$. vivax [27-30]. The latter is the most geographically widespread malaria parasite that causes disease in humans outside of Africa and is especially prevalent in Southeast Asia and the Americas [31, 32]. Individuals in western, eastern and central Africa have long been considered refractory to infection by this parasite because of the high prevalence of the Duffy-negative phenotype [33, 34]. This phenotype is caused by a single nucleotide polymorphism (SNP) in the erythroid-specific promoter region of the DARC (Duffy antigen receptor for chemokines) gene [35], and individuals who are homozygous for the allele carrying this SNP lack the Duffy protein on erythrocytes. However, the dogma of " $P v$ absence in Africa" [36] began to fail a decade ago when evidence began accumulating for $P$. vivax infections in Duffynegative individuals across Africa, and in the intervening time different studies have reported $P$. vivax infections in Mauritania [37, 38], Ethiopia [39, 40], Equatorial Guinea [41], Mali [42], Democratic Republic of Congo [43], Benin [44], Nigeria [45] and Cameroon [27-30]. In Cameroon, the association of $P$. vivax with human infections in both Duffy-positive and -negative individuals has been reported, albeit at low frequencies. However, no study has yet looked at which local malaria vector species is involved in the transmission of $P$. vivax. 
In this study, we aimed to characterize malaria parasites and vectors circulating in an area of seasonal transmission in the Adamawa region. We focused on P. vivax detection as this species was recently reported in other parts of the country, and we conducted entomological surveys to identify its putative vector, which has not been investigated in earlier studies. Our main goal was to examine the potential risk of transmission of $P$. vivax and to determine which local malaria vector species could be implicated in its transmission in this region of Cameroon.

\section{Methods}

\section{Study area}

The study was conducted in the town of Tibati $\left(6^{\circ} 27^{\prime} 57^{\prime \prime} \mathrm{N} ; 12^{\circ} 37^{\prime} 30^{\prime \prime} \mathrm{E}\right)$, which is the capital of Djerem department in the Adamawa region of Cameroon. The population of Tibati is estimated to be 108,502 persons. The town is characterized by a predominantly wet tropical climate with two seasons, a dry season extending from November to February and a rainy season from March to October during which the intensity of transmission is high. The annual rainfall ranges from 1192 to $2023 \mathrm{~mm}$, and the average annual temperature is around $23.6{ }^{\circ} \mathrm{C}$. There is a dense hydrographic network of several rivers, such as the Djerem, Meng and Tomi rivers, in the area around Tibati [46].

The parasitological and entomological surveys were carried out from June to July 2015 and during the same period in 2017, to coincide with the rainy season during which transmission is highest. Blood samples were collected from clinical patients (symptomatic) with fever or a history of fever in 2015 and from asymptomatic individuals in the community in 2017. Patients with clinical malaria were recruited among patients in three randomly selected health facilities: the Missionary Hospital of Ngaoubela, the District Medical Center and the Integrated Medical Center located at around $7 \mathrm{~km}, 600 \mathrm{~m}$ and $100 \mathrm{~m}$ from the city center, respectively. The minimal estimated sample size of 346 participants was determined by the formula $n=T^{2} \times P(1-P) / M^{2}$, where $n=$ sample size; $T=$ confidence level at $95 \%$ (with value at 1.96 ); $P=$ malaria prevalence in the Adamawa region (34.2\%) according to the Programme National de Lutte contre le Paludisme 2019 [8]); and $M=$ margin of error at 5\% (0.05). Blood from asymptomatic carriers was collected from individuals living in randomly selected houses in the community, from eight neighborhoods within the Tibati city perimeter (Malarba, Meng, Ngaoubela, Sabongari, Tella, Wourtababa, Tomi and Yoko) (Fig. 1). Mosquito collection was performed by spraying resting female mosquitoes in randomly selected human dwellings and in houses where blood from asymptomatic carriers was collected, with IRS with pyrethrum in 2015 and 2017, respectively.

\section{Blood and mosquito sampling}

Blood was collected from volunteers of all ages independently of gender and ethnicity. Adults ( $\geq 18$ years old) or legal guardians were asked to provide written informed consent for underaged volunteers $(<18$ years old). Blood was obtained by fingerprick in volumes of 5 and $100 \mu \mathrm{l}$ for thick smears films and dried blood spots on What$\operatorname{man}^{\mathrm{TM}}$ grade 1 and FTA paper (GE healthcare UK Ltd., Amersham, UK), respectively. Thick blood smears were stained with $10 \%$ Giemsa for $20 \mathrm{~min}$ [19] and examined under a light microscope (Leica model DM750; Leica Microsystems GmbH, Wetzlar, Germany) at $100 \times$ magnification, oil immersion, for the detection of asexual and sexual stages of the malaria parasite. Parasitemia was estimated by counting the number of parasites against 500 white blood cells (WBCs), assuming the standard number of $8000 \mathrm{WBC} / \mu \mathrm{l}$ of blood [47]. Blood spots were dried, stored at room temperature in a desiccant container and brought to the Malaria Research Unit for further analysis. Plasmodium-positive patients were treated with an ACT according to the recommendations of the Ministry of Health of Cameroon (National Malaria Control Program [NMCP]).

Mosquito collections were carried out in the morning from 6:00 to 10:00 a.m., and written informed consent was obtained from household owners prior to the start of collection. A white sheet was used to cover the floor and all flat surfaces, and the pyrethrum residual (composition: permethrin, $0.25 \%$; piperonyl butoxide, $0.34 \%$; tethramethrin, $0.20 \%$; D-phenothrin, $0.01 \%$ ) was sprayed into all the corners of the house. After $15 \mathrm{~min}$, mosquitoes that had fallen onto the sheet were collected, counted and identified at the genus or species level. Anopheles mosquitoes were identified using morphological identification keys [48, 49]. All female Anopheles specimens were dissected individually, and the carcasses and headthoraces were stored separately in tubes containing a desiccant, archived and kept at $-20{ }^{\circ} \mathrm{C}$ for further molecular analysis.

\section{Blood and mosquito DNA extraction}

DNA was isolated from blood spots collected in 2015 using the protocol provided by the manufacturer (Schleicher-Schuell BioScience GmbH, Dassel, Germany) [50]. Briefly, three 5-mm discs of a dried blood spot were cut out using a sterile paper punch and transferred to a $1.5-\mathrm{ml}$ sample tube filled with $500 \mu \mathrm{l}$ of sterile water. The tubes were vortexed three times for at least $5 \mathrm{~s}$ each time and centrifuged at $2000 \mathrm{rpm}$ for few seconds. Using sterile forceps, the paper discs were transferred into a 


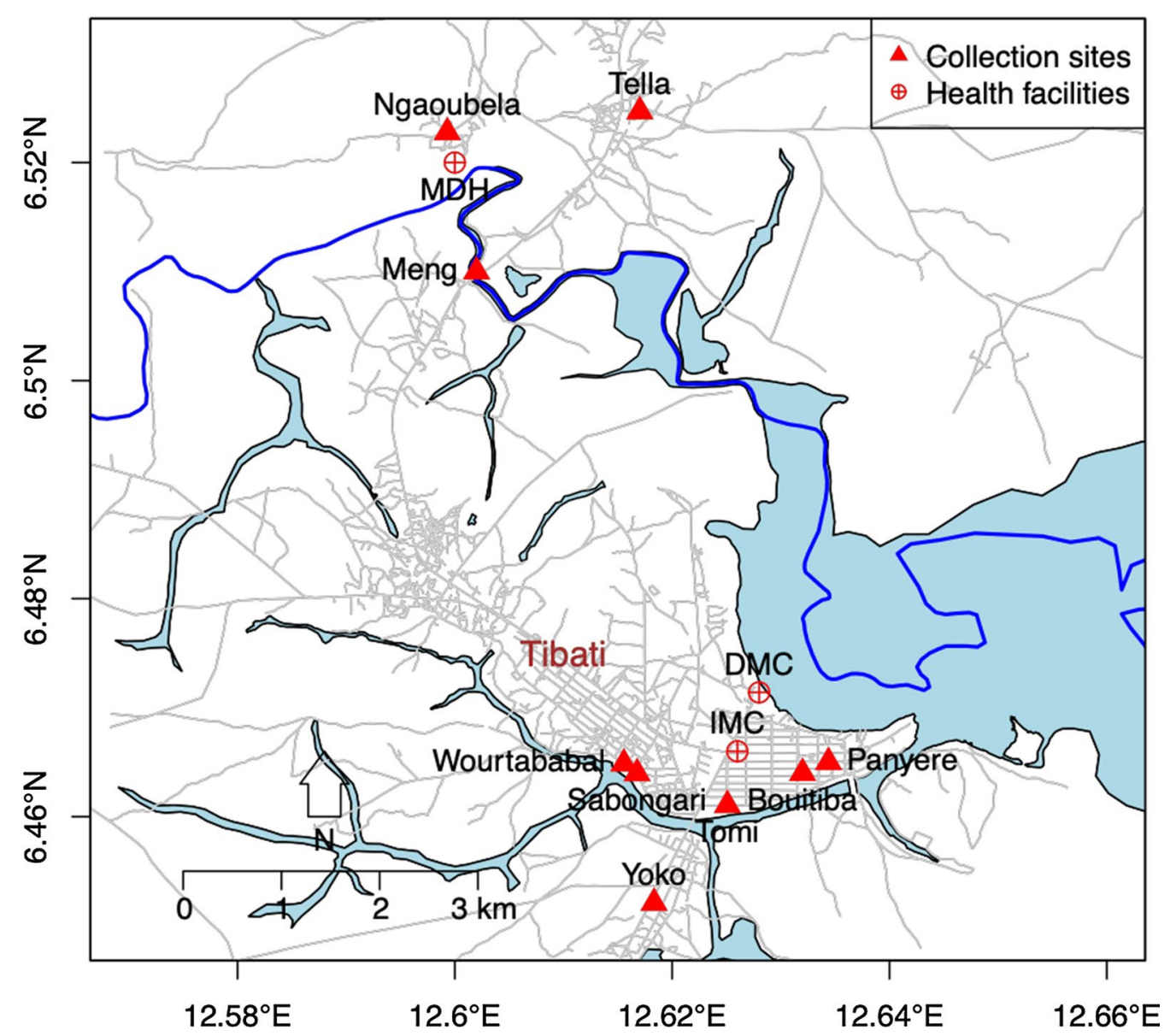

Fig. 1 Map of Tibati showing collection sites. Blood samples were collected from symptomatic malaria patients in three health facilities: the Missionary hospital of Ngaoubela (MDH), District Medical Center (DMC) and the Integrated Medical Center (IMC). Blood samples were collected from asymptomatic persons in the community in eight neighborhoods of Tibati: Malarba, Meng, Ngaoubela, Sabongari, Tella, Wourtababa, Tomi and Yoko, which were the same neighborhoods that mosquito collections were performed

0.5 - $\mathrm{ml}$ tube containing $120 \mu \mathrm{l}$ sterile water and incubated at $95{ }^{\circ} \mathrm{C}$ in a heat block for $15 \mathrm{~min}\left(\right.$ Gene Amp ${ }^{\circledR}$; Applied Biosystems, Foster City, CA, USA). After incubation, the tubes were centrifuged for few seconds, following which the spots were removed, and the extracted DNA was stored at $-20^{\circ} \mathrm{C}$ for molecular diagnosis.

To optimize the DNA extraction and allow for a better separation of DNA from some nucleases, we used the Qiagen DNeasy ${ }^{\circledR}$ Blood and Tissue Kit (Hilden, Germany) to isolate DNA from the blood samples collected in 2017, in accordance with the manufacturer's instructions, and resuspended the isolated DNA in $60 \mu \mathrm{l}$ elution buffer.

Genomic DNA from individual mosquito carcasses was isolated using the $2 \%$ cetyltrimethyl ammonium bromide (CTAB) method, following the protocol of Collins et al. [51]. DNA from the head-thoraces was isolated using the Qiagen DNeasy ${ }^{\circledR}$ Blood and Tissue Kit according to the manufacturer's instructions, and resuspended in $50 \mu \mathrm{l}$ elution buffer.

\section{Molecular identification of Plasmodium and Anopheles species}

The Plasmodium infection status of blood collected in 2015 was determined by a multiplex PCR [52], which targets the 18S small subunit ribosomal RNA. Reaction mixtures were prepared with $5 \mu$ of eluted DNA and the Taq Hot Start Master mix (Qiagen), following the manufacturer's instructions, and samples were amplified as previously described [52]. The amplified products were visualized by electrophoresis in a $2 \%$ agarose gel and stained with SYBR dye (Green Nucleic Acid stain; Biotium, Hayward, CA, USA). The expected amplicon size was $276 \mathrm{bp}$ for $P$. falciparum, $300 \mathrm{bp}$ for $P$. vivax, $375 \mathrm{bp}$ for $P$. ovale and $412 \mathrm{bp}$ for $P$. malariae.

Genomic DNA from mosquito carcasses was used to identify members of the Anopheles gambiae complex by 
PCR-restriction fragment length polymorphism (RFLP) [53] and members of Anopheles funestus group were identified according to the protocol of Koekemoer et al. [54]. All PCR products were analyzed in a $2 \%$ agarose gel.

A simple quantitative PCR (qPCR) was performed to identify Plasmodium-infected mosquitoes, as previously described [55]. Selected genes were amplified in order to discriminate between Plasmodium species, including the aquaglyceroporin gene (AQP, AJ413249.1) for P. falciparum, the enoyl-acyl carrier protein reductase gene (ECPR, AY423071.1) specific for P. vivax, the P25 ookinete surface protein gene (Pos25, AB074976.1) for $P$. ovale and the circumsporozoite gene (CS, S69014) targeting $P$. malariae [56]. Reaction mixtures were performed with $1 \mu \mathrm{l}$ of template DNA in a final volume of $10 \mu \mathrm{l}$ with EvaGreen ${ }^{\circledR}\left(5 \times\right.$ HOT Pol EvaGreen ${ }^{\circledR}$ RT PCR Mix Plus; Euromodex, Souffelweyersheim, France) and amplified in a 7300 Real-time PCR system (Applied Biosystems). A dissociation curve was used to estimate the specific melting temperature for each reaction.

For the samples from 2017, An. gambiae complex and the members of An. funestus group were identified as described above. Detection of Plasmodium in blood spots and mosquito head-thoraces for these samples was achieved by multiplex qPCR in the Lightcycler 96 realtime PCR system, according to the protocol published by Mangold et al. [57], with slight modifications. The final volume of the reaction mixture was $10 \mu \mathrm{l}$, containing $2 \mu \mathrm{l}$ of template DNA. The PCR conditions consisted of an initial preincubation step at $95^{\circ} \mathrm{C}$ for $10 \mathrm{~min}$; followed a three-step amplification of $95{ }^{\circ} \mathrm{C} / 10 \mathrm{~s}\left(\mathrm{ramp} 4.4{ }^{\circ} \mathrm{C} / \mathrm{s}\right)$, $50{ }^{\circ} \mathrm{C} / 5 \mathrm{~s}\left(2.2{ }^{\circ} \mathrm{C} / \mathrm{s}\right)$ and $72{ }^{\circ} \mathrm{C} / 20 \mathrm{~s}\left(4.4{ }^{\circ} \mathrm{C} / \mathrm{s}\right)$, for 45 cycles. Amplification was directly followed by a melting program of $95{ }^{\circ} \mathrm{C} / 120 \mathrm{~s}\left(2.2{ }^{\circ} \mathrm{C} / \mathrm{s}\right), 68{ }^{\circ} \mathrm{C} / 120 \mathrm{~s}\left(2.2{ }^{\circ} \mathrm{C} / \mathrm{s}\right)$ and $90{ }^{\circ} \mathrm{C} / 1 \mathrm{~s}\left(\operatorname{ramp} 0.2{ }^{\circ} \mathrm{C} / \mathrm{s}\right.$ with 15 readings $\left./{ }^{\circ} \mathrm{C}\right)$, and a stepwise temperature increase of $0.03{ }^{\circ} \mathrm{C} / \mathrm{s}$ until $95{ }^{\circ} \mathrm{C}$. The 18S rRNA gene of the P. falciparum 3D7 clone was used as positive control for Plasmodium species differentiation.

\section{Sequencing}

The qPCR products of Plasmodium-positive mosquitoes were sequenced using the Big Dye Terminator v3.1 Sequencing Kit (Applied Biosystems) and run on an Applied Biosystems 3130xl Sequencer at the GenSeq technical facility of the Institut des Sciences de l'Evolution de Montpellier. Sequences were verified using SeqScape software (Applied Biosystems).

\section{Statistical analysis}

Data were stored in Microsoft Office Excel files (Microsoft Corp., Redmond, WA, USA) and transferred into GraphPad Prism 7 (GraphPad Software Inc., San Diego,
CA, USA) for statistical analyses. The Mann-Whitney test was used to compare mean parasite densities according to clinical status, for both trophozoites and gametocytes. The Chi-square test was used to compare the prevalence of Plasmodium infections among population age groups and mosquito species. The non-parametric Kruskal-Wallis test was used to assess differences in parasite densities between age groups. The significance threshold was set at alpha $=0.05$. The relative risk (RR) was computed to estimate the protection associated with LLIN use. R software version 3.5.3 with maptools and ggplot2 packages was used to generate the map and figures, respectively (R Foundation for Statistical Computing, Vienna, Austria), while melting temperatures of qPCR-positive controls were retrieved by using functional bases (without package).

\section{Result}

\section{Characteristics and prevalence of malaria infections} in the studied population

A total of 1367 participants were enrolled in this study, 418 through the health centers (symptomatics) and 949 at the community level (asymptomatics). The main characteristics of the participants are detailed in Table 1.

The median age of participants was 12 years (range 21 days to 85 years). The sex ratio (male/female) was $0.7(558 / 809)$. Mean parasite densities were significantly higher in symptomatic patients from the health centers than in asymptomatic individuals recruited in the community, for both sexual $(6199 \pm 2626$ vs $38.75 \pm 7.85$, Mann-Whitney $U=1992 ; \quad P<0.0001)$ and asexual stages $(34,164 \pm 5332$ vs $5964 \pm 867.8$; Mann-Whitney $U=22,168 ; P<0.0001)$. The mean asexual parasite densities significantly decreased with age in blood samples from both symptomatic and asymptomatic participants (Kruskal-Wallis test, $P<0.001$; Fig. 2).

Of the 1367 samples, malaria diagnostic tools revealed 752 (55.01\%) infections with Plasmodium. The infection rate was $41.8 \%(175 / 418)$ in samples from symptomatic patients and $60.8 \%$ (577/949) in samples from asymptomatic individuals, which is significantly different $\left(X^{2}=41.21 ; P<0.0001\right)$. Plasmodium falciparum was the most prevalent Plasmodium species collected during both collection periods and represented 98.8 and $92.9 \%$ of human infections in 2015 and 2017, respectively. Plasmodium malariae and P. ovale each accounted for $0.6 \%$ of clinical infections. In comparison, in samples from asymptomatic persons a higher prevalence was recorded for P. malariae $(22.9 \%)$ while P. ovale was rare $(0.9 \%)$. Mixed infections were only found in asymptomatic carriers and were mostly represented by $P$. falciparumP. malariae (92/96, 95.8\%). No P. vivax infection was detected in any blood sample. 
Table 1 Characteristics of the study population and infection parameters

\begin{tabular}{lll}
\hline Parameters & $\begin{array}{l}2015 \\
\text { Health centers } \\
\text { (symptomatics) }\end{array}$ & $\begin{array}{l}\text { Community } \\
\text { (asymptomatics) }\end{array}$ \\
\hline $\begin{array}{l}\text { Sample size } \\
\text { Median age, years (IQR) }\end{array}$ & 418 & 949 \\
$\begin{array}{l}\text { Infections per age group, } n(\%): \\
<5 \text { years }\end{array}$ & $15(3-30)$ & $12(6-23)$ \\
5-15 years & $83(58.5)$ & $110(62.1)$ \\
$>15$ years & $40(58.8)$ & $310(71.4)$ \\
Total number persons infected & $52(25)$ & $157(46.4)$ \\
Plasmodium infections, $n(\%)$ & $175(41.8)$ & $577(60.8)$ \\
$\begin{array}{l}\text { P. falciparum } \\
\text { P. malariae }\end{array}$ & $173(98.8)$ & $441(76.4)$ \\
P. ovale & $1(0.6)$ & $39(6.8)$ \\
Co-infections & $1(0.6)$ & $1(0.2)$ \\
Mean trophozoite density $(/ \mu \mathrm{l})(\mathrm{SD})$ & $34,164(63,541)$ & $5964(18,429)$ \\
Mean gametocyte density $(/ \mu \mathrm{l})(\mathrm{SD})$ & $6199(18,956)$ & $38.75(97.2)$ \\
\hline
\end{tabular}

IQR interquartile, $S D$ standard deviation

Malaria prevalence decreased with age in both asymptomatic individuals and symptomatic patients, and individuals older than 15 years were less infected $\left(\chi^{2}=48.39\right.$ and $X^{2}=49.91$ respectively; $\left.P<0.001\right)$. Gametocyte carriage was significantly higher in asymptomatic individuals than in symptomatic patients (16.2 vs 10.7\%, $\left.X^{2}=6.96, P=0.008\right)$. Heterogeneity in malaria infection was observed between neighborhoods, with infection rates varying from 48.2 to $71.2 \%$ inSabongari and Ngaoubela, respectively $(P=0.011$; Table 2$)$. A total of $53 \%(503 / 949)$ of asymptomatic carriers reported using LLINs and the coverage of LLINs varied from $21.1 \%$ in Yoko to $88 \%$ in Meng (Table 2). LLIN use based on selfreport only conferred slight protection: malaria infection among LLIN users was only 7\% less than that among non-users (non-significant difference; $\mathrm{RR}=0.89,95 \%$ confidence interval [CI] 0.58-0.98); however, the difference varied with collection site, with up to $20 \%$ protection found in Malarba.

\section{Mosquito species composition}

A total of 592 Anopheles were collected during both study periods. According to morphological criteria, the two species complexes identified were An. gambiae (s.l.) and An. funestus (s.l.). Molecular identification of specimens of An. gambiae sibling species showed that this fauna was composed of two species: An. gambiae (212; 35.8\%) and An. coluzzii (172; 29.1\%). Anopheles funestus (s.s.) was the only species identified within the An. funestus group and represented 35.1\% (208/592) of anopheline mosquitoes. The distribution of the three species according to the two

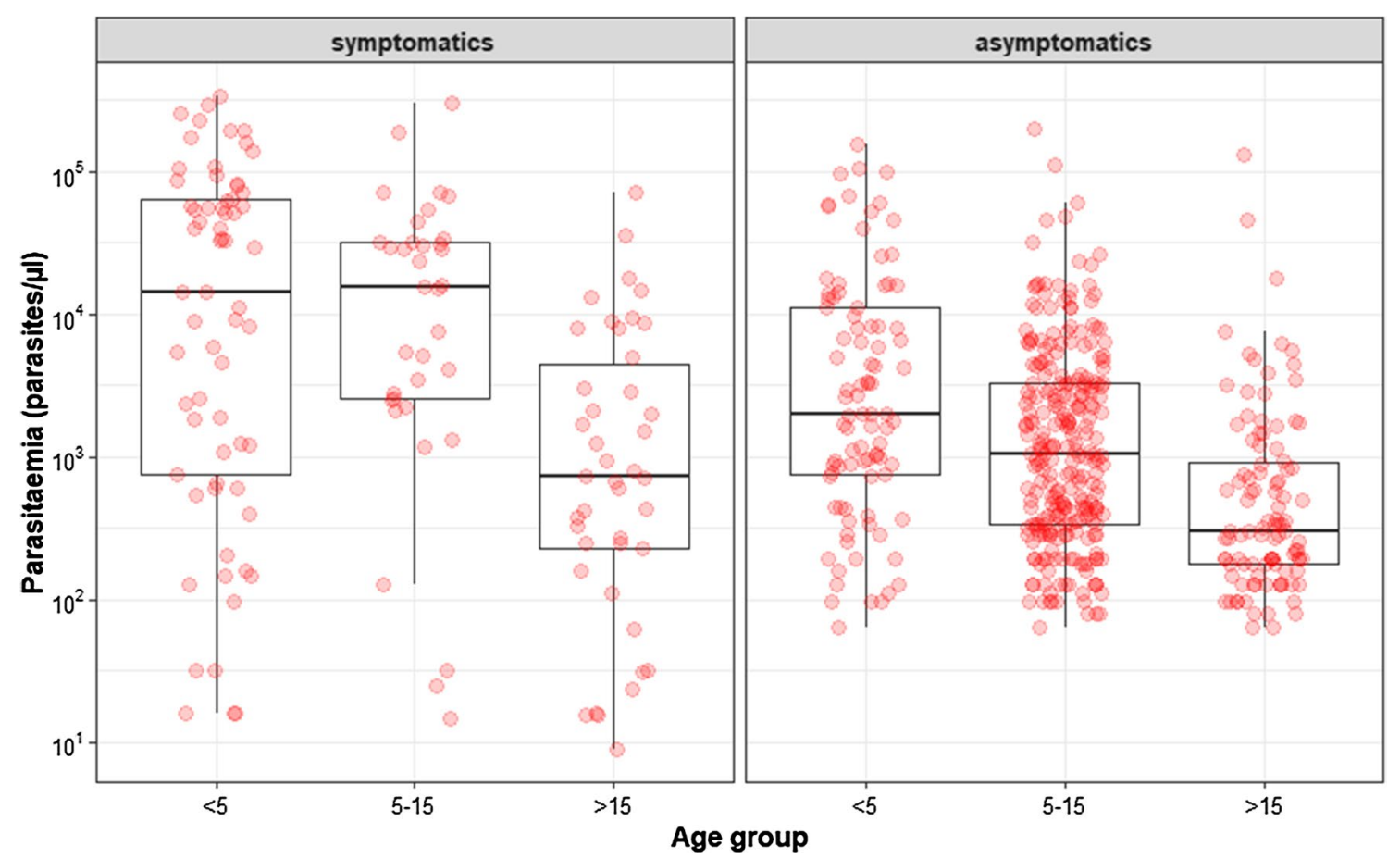

Fig. 2 Boxplot of parasite densities for each age group in symptomatic and asymptomatic individuals 
collection periods is shown in Fig. 3. No hybrid between An. coluzzii and An. gambiae mosquitoes was detected.

\section{Vector infection rates}

Head-thoraces of the 592 Anopheles were subjected to qPCR to detect infected mosquitoes. The results were obtained according to the melting temperature value given by an optical reading of the corresponding melting curve. In total, 26 (4.39\%) Anopheles mosquitoes were infected by a Plasmodium sp., of which 24 could be clearly identified according to melting temperature. However, the remaining two samples (YK60 and NG239) gave a bimodal curve and were assigned as putative co-infection. YK60 was suspected to be $P$. malariae/P. ovale coinfection, with the main peak assigned to $P$. malariae and the minority peak to $P$. ovale (Fig. 4a). Further sequencing analysis identified the YK60 sample as a $P$. malariae monoinfection. For the NG239 sample (Fig. 4b), the melting temperature of the minority peak was assigned to $P$. falciparum, while the main peak did not match any Plasmodium sp. according to Mangold et al. [57]. The sequencing analysis revealed that the NG239 sample was a $P$. falciparum monoinfection.

The overall infection rate varied from 4.07 to $4.72 \%$ between mosquito species, and no significant difference was observed between species $\left(\chi^{2}=0.046, P=0.97\right.$; Table 3). The infection rate did not differ between the two collection periods $\left(x^{2}=3.049, P=0.08\right)$. Variation in mosquito infection rate was observed between neighborhoods in 2017, with Yoko (5/9) recording the highest number of infected mosquitoes (Table 3).

All Plasmodium-positive specimens were monoinfected, either with $P$. falciparum (61.5\%), P. malariae $(19.2 \%)$ or $P$. ovale (15.4\%). A single sample was found by qPCR to be positive for An. coluzzii with P. vivax.

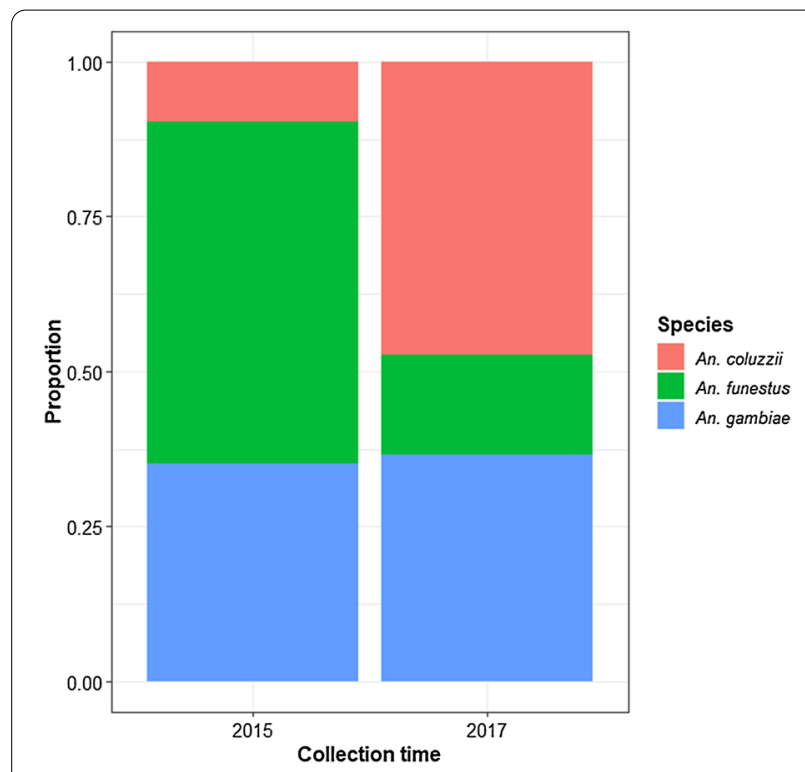

Fig. 3 Distribution of Anopheles mosquitoes according to collection time

All Plasmodium-positive mosquitoes were processed for sequencing, and the sequence alignment of the $P$. vivax infection is presented in Fig. 5.

\section{Discussion}

This study was performed to assess epidemiological and entomological parameters of malaria in Tibati, a locality situated in the Adamawa region of Cameroon. At the present time, little data exist on malaria in this area.

The incidence of malaria is known to vary according to epidemiological settings, age and clinical status of the study population and season, as well as with treatment guidelines and control interventions. Malaria

Table 2 Malaria prevalence, long-lasting insecticidal net usage and infection rate of mosquitoes according to neighborhoods in 2017

\begin{tabular}{|c|c|c|c|c|c|c|}
\hline \multirow[t]{2}{*}{ Neighborhoods } & \multicolumn{2}{|c|}{ Blood samples } & \multicolumn{2}{|c|}{ LLIN usage } & \multicolumn{2}{|c|}{ Mosquitoes } \\
\hline & $N$ & IR (\%) & Use & Frequency (\%) & $N$ & IR (\%) \\
\hline Malarba & 150 & 66.0 & 46 & 30.7 & 40 & 2.5 \\
\hline Meng & 183 & 61.2 & 161 & 88.0 & 63 & 1.6 \\
\hline Ngaoubela & 111 & 71.2 & 77 & 69.4 & 78 & 1.3 \\
\hline Sabongari & 83 & 48.2 & 48 & 57.8 & 3 & 0 \\
\hline Tella & 100 & 57.0 & 39 & 39.0 & 0 & 0 \\
\hline Tomi & 107 & 65.4 & 45 & 42.1 & 24 & 4.2 \\
\hline Wourtabbal & 66 & 53.0 & 56 & 84.8 & 0 & 0 \\
\hline Yoko & 147 & 57.1 & 31 & 21.1 & 96 & 5.2 \\
\hline Total & 947 & 60.8 & 503 & 53.0 & 304 & 2.9 \\
\hline
\end{tabular}

IR Plasmodium infection rate, LLIN long-lasting insecticidal nets, $N$ number of samples collected 

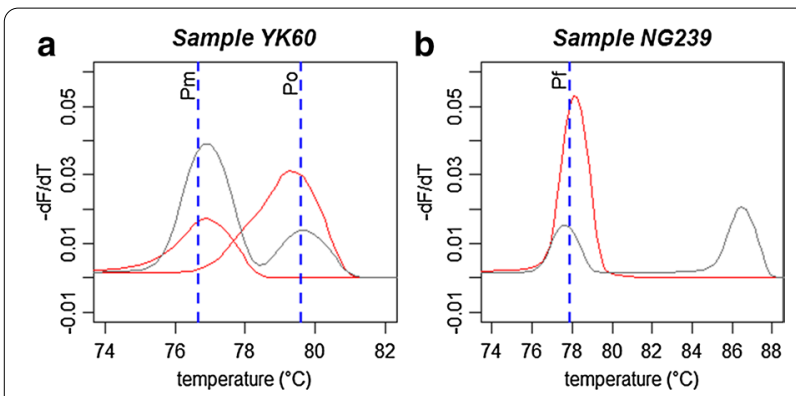

Fig. 4 Melting curve peak of the YK60 and NG239 samples identified as being infected by a Plasmodium sp. The $x$-axis represents the melting temperature $(\mathrm{Tm})$ and the $y$-axis represents the results of quantitative PCR on the Lightcycler real-time PCR system ( $d F / d T$ negative derivative of the fluorescence/derivative temperature). Each red and blue curve represents the Tm of each Plasmodium falciparum-positive control. The green curve represents the Tm of the sample

prevalence in our study area varied from $42 \%$ in symptomatic patients to $61 \%$ in asymptomatic individuals in the community. This prevalence value is 15 -fold higher than that reported by Songue et al. [25] in Meidougou, a village located within the same Adamawa region, where the authors reported a $3.6 \%$ infection rate based on microscopy studies of symptomless children aged $<10$ years [25]. Other studies in Bolifamba, an area with a similar epidemiological setting, have identified an infection rate of $>50 \%$ by microscopy [58]. Malaria prevalence in studies in which malaria infections were diagnosed using PCR methodology also show large variations, with FruCho et al. [28] reporting a malaria prevalence of $32 \%$ among asymptomatic carriers in the village of Bolifamba, and Russo et al. [29] reporting a 14\% prevalence among febrile outpatients in Dschang, an altitudinal city in the West region. Although microscopy remains the "gold standard" tool for diagnosing malaria in the field, this approach has certain limitations, including inaccurate quality assurance and misdiagnosis of low parasitemia as the detection threshold by microscopy is about 50 parasites/ $\mu l$. PCR-based methods are more sensitive and specific than the microscopic examination of thick blood smears, particularly in cases of low-density or mixed parasite infections that are frequent in asymptomatic carriers $[59,60]$. Accordingly, $9 \%$ of the negative blood smears by microscopic examination were found to be positive upon molecular analysis in our study.

Almost half $(42 \%)$ of the patients who went to the health care centers for consultation/treatment were diagnosed with malaria infection. Malaria remains the primary cause of fever in febrile patients, but other infections, such as Dengue, Chikungunya or Zika, likely also circulate in the area. Indeed, clinical symptoms of malaria are non-specific, and inter-epidemic arboviral infections are regularly reported in central Africa [61-64]. Accurate diagnosis of Plasmodium is therefore crucial for providing appropriate treatment regimens to patients. Determining the burden of malaria is also important for applying effective malaria control strategies in endemic settings and for determining their efficacy. In Cameroon, a nation-wide mass distribution campaign of LLINs took place in 2011, 2015 and 2019, and the NMCP reports a LLIN coverage of $>80 \%$ [65]. In our study, 53\% (503/949) of asymptomatic individuals reported owning a bed net, but of these, $57.5 \%(289 / 503)$ were infected with malaria. It has been reported earlier that bed net coverage is not associated with asymptomatic $P$. falciparum prevalence [66]. It must also be considered that bed net coverage may be less than that acknowledged by the volunteers in our study. Barriers to mosquito net use have been described in previous studies, and a larger sensitization of households would be necessary to prevent the continuous spread of malaria $[67,68]$.

Asymptomatic infections represent the major reservoir of parasites [69]. In our study, we identified asymptomatic infection in $60.8 \%$ of blood samples collected from individuals at the community level, which indicates that malaria transmission is high in the area. Asymptomatic infections are associated with parasite exposure

Table 3 Number of mosquitoes collected and of Plasmodium-positive mosquitoes according to quantitative PCR

\begin{tabular}{|c|c|c|c|c|c|c|c|c|c|c|c|c|c|c|c|c|}
\hline \multirow[t]{3}{*}{ Anopheles spp. } & \multicolumn{7}{|c|}{ June 2015} & \multicolumn{6}{|c|}{ July 2017} & \multirow{2}{*}{\multicolumn{3}{|c|}{ Total }} \\
\hline & \multicolumn{3}{|c|}{ Mosquitoes } & \multicolumn{4}{|c|}{ Plasmodium sp. } & \multicolumn{3}{|c|}{ Mosquitoes } & \multicolumn{3}{|c|}{ Plasmodium sp. } & & & \\
\hline & $N$ & $\mathrm{~N}+$ & $\%$ & $P f$ & Pm & Po & Pv & $N$ & $N+$ & $(\%)$ & $P f$ & $P m$ & Po & $N$ & $\mathrm{~N}+$ & $\%$ \\
\hline An. gambiae & 101 & 7 & 6.93 & 4 & 3 & 0 & 0 & 111 & 3 & $(2.7)$ & 2 & 0 & 1 & 212 & 10 & 4.72 \\
\hline An. coluzzii & 28 & 2 & 7.14 & 1 & 0 & 0 & 1 & 144 & 5 & (3.47) & 2 & 1 & 2 & 172 & 7 & 4.07 \\
\hline An. funestus (s.s.) & 159 & 8 & 5.03 & 6 & 1 & 1 & 0 & 49 & 1 & $(2.04)$ & 1 & 0 & 0 & 208 & 9 & 4.33 \\
\hline Total & 288 & 17 & 5.9 & 11 & 4 & 1 & 1 & 304 & 9 & (2.96) & 5 & 1 & 3 & 592 & 26 & 4.39 \\
\hline
\end{tabular}

$N$ Number of collected mosquitoes, $N+$ number of Plasmodium-positive mosquitoes, $\%$ percentage of infected mosquitoes, Pf Plasmodium falciparum, Pm Plasmodium malariae, Po Plasmodium ovale, Pv Plasmodium vivax 
Alignment: Plasmodium vivax enoyl-acyl carrier protein reductase gene

$\ldots|\ldots| \ldots|\ldots| \ldots|\ldots| \ldots|\ldots| \ldots|\ldots| \ldots|\ldots| \ldots|\ldots| \ldots|\ldots| \ldots|\ldots|$

$10 \quad 20 \quad 30 \quad 40 \quad 50$

60

70

AY423071.1 ATGCACGTGA GAAGAGTGGT CCAGTTGGCG ACCCTACTGC TGTACATCGC CTCTGTCAGC GCGATGCTGA P4G2 $F$

P4G2_R

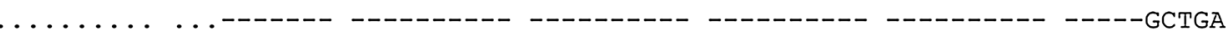

.............GAGGGT CCAGTtGGCG ACCCTACTGC TGTACATCGC CTCTGTCAGC GCGATGCTGA

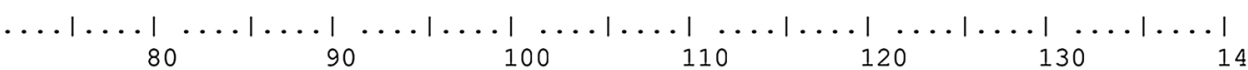

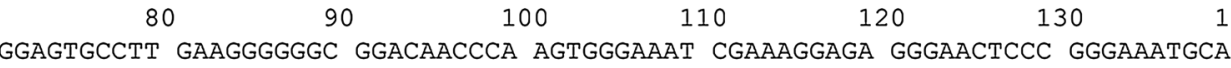

$\begin{array}{lll}\text { AY423071.1 GGAGTGCCTT GAAGGGGGGC GGACAACCCA AGTGGGAAAT CGAAAGGAGA GGGAACTCCC GGGAAATGCA } \\ \text { P4G2 F } & \text { GGAGTGCCTT GAAGGGGGGC GGACAACCCA AGTGGGAAAT CGAAAGGAGA GGGAACTCCC GGGAATGCA }\end{array}$

P4G2_R GGAGTGCCTT GAAGGGGGGC GGACAACCCA AGTGGGAAAT CGAAAGGAGA GGGAACTCCC GGGAAATGCA

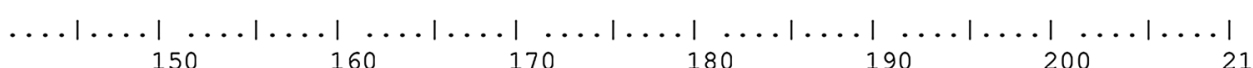

$\begin{array}{lllllll}150 & 160 & 170 & 180 & 190 & 200 & 210\end{array}$

AY423071.1 GTTCATTACC AGCAAAGCAA TAAAGGGGGT AGCTCATAAG AGGAAAATCT CACAACATTC ATCCCCTGCA P4G2 F GTTCATTACC AGCAAAGCAA TAAAGGGGGT AGCTCATAAG AGGAAAATCT CACAACATTC ATCCCCTGCA P4G2_R GTTCATTACC AGCAAAGCAA TAAAGGGG AGCTCATAAG AGGAAAATCT CACAACATTC ATCCCCTGCA $\ldots|\ldots| \ldots|\ldots| \ldots|\ldots| \ldots|\ldots| \ldots|\ldots| \ldots|\ldots| \ldots|\ldots| \ldots|\ldots| \ldots|\ldots|$ | $\ldots 1$ $220 \quad 230 \quad 240 \quad 250 \quad 260 \quad 270 \quad 280$

AY423071.1 GAACACATGG TGAGTGAGCA AAGTGGGCAA GCGGAAGGGA TAAATGGAAA GGGAGAACCC CTTGGAGACA P4G2_F GAACACATGG TGAGTGAGCA AAGTGGGCAA GCGGAAGGGA TAAATGGAAA GGGAGAACCC CTTGGAGACA P4G2 R GAACACATGG TGAGTGAGCA AAGTGGGCAA GCGGAAGGA TAAATGGAAA GGGAGACCC CTTGGAGACA $\ldots|\ldots| \ldots|\ldots| \ldots|\ldots| \ldots|\ldots| \ldots|\ldots| \ldots|\ldots| \ldots|\ldots| \ldots|\ldots| \ldots|\ldots|$ $\begin{array}{llllll}290 & 300 & 310 & 320 & 330 & 340\end{array}$

AY423071.1 TCTGCTTCAT CGCGGGAGTG GGAGACACCA ATGGATACGG GTGGGGAATC GCAAAAGAAT TGAGCAAAAA P4G2_F TCTGCTTCAT CGCGGGAGTG GGAGACACCA ATGGATACGG GT $\ldots \ldots \ldots \ldots \ldots \ldots \ldots$

P4G2_R

Fig. 5 DNA sequence alignment of the P. vivax sample isolated from an infected Anopheles coluzzii sampled in 2015, referred to as sample P4G2, with the reference DNA sequence PV_ECPR (accession number AY423071.1). P4G2_F and P4G2_R represent the forward and reverse sequences, respectively. Numbering corresponds to that of the Pv_ECPR sequence. No mismatchs were found

and decrease with age as prolonged exposure to malaria leads to the development of partial immunity to the disease $[69,70]$. We noted that asymptomatic carriage was higher in the age group 5-15 years, which is in line with the development of acquired immunity in the older children. The lower prevalence of asymptomatic infections among individuals aged $>15$ years likely represents the increased ability of older individuals to control parasite growth due to stronger anti-parasite immunity. However, some infections in this age group were certainly missed because asymptomatic infections are often low-density infections and undetectable through microscopy examination and even PCR testing [66, 69, 71]. Accordingly, parasite densities decreased with age in asymptomatic individuals. In symptomatic patients, lower parasite loads were found in the older age group ( $>15$ years), but densities were similar in children aged $<5$ years and those aged 5-15 years, indicating that the parasite threshold to develop malaria symptoms is lower in older individuals, as previously observed [72]. Parasite burden contributes to the pathogenesis of the disease, and pyrogenic thresholds of parasitemia are often used to correlate fever with malaria, with thresholds varying with transmission intensity and age [73, 74]. Spatial heterogeneity in malaria infections was observed in our study, with Yoko presenting the highest malaria prevalence. This finding suggests hotspots of transmission in our study area. Multiple factors can explain this heterogeneity, such as proximity to breeding sites, urbanization or housing characteristics [75-77]. It is tempting to state that such high transmission clusters should be the focus of targeted control, but past interventions targeting hotspots of transmission failed to influence malaria transmission dynamics [78].

In this study, we identified three Plasmodium species in human blood samples, among which $P$. falciparum was the most predominant vector species, accounting for over $95 \%$ of malaria infections. These data are consistent with previous reports in other epidemiological settings, indicating that $P$. falciparum predominates across Cameroon $[29,79,80]$. Plasmodium malariae and $P$. ovale were found as mono- and co-infections with $P$. falciparum, but at low prevalence and these species were rarely found in symptomatic individuals. In the present study, no $P$. vivax infection was detected either in symptomatic or asymptomatic samples. Circulation of $P$. vivax in Cameroon has been recorded since 2014 in different epidemiological settings, even though previous reports documented $P$. vivax infections only in travellers returning 
from Cameroon $[81,82]$. In previous reports, $P$. vivax infections in Cameroon were mostly identified at low frequencies, representing < 15\% (13/269) of malaria infections in Bolifamba, southwest region [28], 6\% (27/484) in Dschang, west Cameroon [29] and 4\% (8/201) in five forested south parts of the country [27]. The latest study reported 23\% (10/43) of $P$. vivax infections among symptomatic patients seeking medical attention at the New Bell district hospital in Douala, Littoral region [30]. Our failure to detect $P$. vivax in the present study suggests that the parasite circulates at very low frequency; as such, larger samples would be necessary to confirm this species in the area. The prevalence of $P$. vivax in Africa differs between epidemiological settings, and it has been suggested that $P$. vivax is more prevalent in areas with lower malaria burden [83].

We performed entomological surveys to identify mosquito vectors responsible for malaria transmission in Tibati. To date, six main vector species, namely An. gambiae, An. coluzzii, An. funestus, An. arabiensis, An. nili and An. moucheti moucheti, have a recognized role in Plasmodium transmission in Cameroon [2, 6, 84]. In the present study, three of these species were identified: $A n$. funestus, An. gambiae and An. coluzzii. These data are consistent with previous reports that indicated a large distribution of these three main vectors across the country $[6,15,85-89]$. Anopheles funestus was more prevalent in 2015 than in 2017 (55.2 vs 16\%, respectively), and the change in the density of this species is likely due to modifications of environmental cues, such as the presence of permanent breeding sites (e.g. lakes and rivers with emergent vegetation) that are favorable for the proliferation of this mosquito species[49, 90]. This observed decrease in the density of An. funestus mosquitoes benefited An. coluzzii, which represented 9.7\% of collected anophelines in 2015 and $47.4 \%$ in 2017. The presence of An. gambiae was stable over the two collection periods. The study area is irrigated by the Meng river and is characterized by the presence of agricultural and fish farming sites that create temporary sites which are favorable for the development of An. gambiae (s.l.), including An. gambiae and An. coluzzii [91, 92]. Anopheles coluzzii has a known high capacity of adaptation in urban environments [93-95], and modifications to the habitat in Tibati (e.g. deforestation, house construction, home improvement) that occurred during the 2 years between the studies have probably contributed to the creation of breeding sites more suitable for An. coluzzii. Nevertheless, the use of the IRS method, which is a widely used method for sampling endophilic mosquitoes, could have favored the collection of endophilic resting Anopheles over other mosquito species.
We found that Plasmodium infection rates did not differ between An. gambiae, An. coluzzii and An. funestus, and thus these three species are considered to transmit malaria at equal efficiency. Sporozoite infection rates fell within the range reported in a previous study conducted in the Adamawa region [87] and in other studies conducted in different parts of the country $[2,84]$. A slight decrease in the overall infection rate was observed between 2015 and 2017 (5.9 vs 4.39\%; $X^{2}=2.791$, $P=0.0948$ ); this reduction, although not significant, could be due to the use of LLINs following the massive country-wide distribution campaign in 2015 [96]. The percentage of infected mosquitoes sampled in 2017 varied between neighborhoods, with the highest infection rate recorded in Yoko (5.2\%), which could be explained by a high malaria prevalence and the lower LLIN coverage (21.1\%) in this neighborhood.

All three mosquito species were mono-infected with P. falciparum, $P$. ovale, $P$. malariae and $P$. vivax. A single $A n$. coluzzii mosquito was carrying $P$. vivax and the fact that only one mosquito was infected by $P$. vivax confirms the low circulation of this species in our study area. Further longitudinal studies or more in-depth sampling would increase the probability to detect $P$. vivax infections in both human and mosquito populations, but it remains that this one mosquito represents the first report of Anopheles infection by $P$. vivax in Cameroon. Transmission of $P$. vivax by anopheline mosquitoes has already been reported in sub-Saharan Africa, but never by $A n$. coluzzii. Mosquito infections with $P$. vivax have been reported for An. arabiensis in Mauritania [97], Madagascar [98, 99] and Ethiopia [100], for An. funestus in Madagascar [98, 101], Kenya [102] and for An. gambiae in Kenya [102]. Also, a study conducted in Angola [41] and Equatorial Guinea identified $P$. vivax infections in mosquitoes, but identification of the vector species was not recorded [41]. Interestingly, in this latter study, the authors reported a significantly higher prevalence of P. vivax infection in mosquitoes (10.99\%) as compared to human population (4.55\%) [41]. The $P$. vivax-infected mosquito we identified was an An. coluzzii specimen, a species that has shown greater susceptibility to malaria infection in a study from Cameroon [55]. Plasmodium vivax can then be considered to circulate in the study area and may also be underestimated, as a proportion of $P$. vivax infections in humans are "hidden" since hypnozoites lie dormant in the liver for several months (or years) where they are undetected.

A limitation to this study is that mosquito samples were obtained at a single collection time and, therefore, the results only provide a one-shot picture of malaria transmission in the study site. Longitudinal surveys would be necessary to follow the dynamics of malaria transmission 
and, particularly, will be crucial to perform parasitological and entomological surveys before and after the implementation of control interventions, such as LLIN distribution. A second limitation is that sample sizes were small, which is possibly the reason we did not detect $P$. vivax infection in the human population. Regular monitoring of malaria infections will be necessary to assess the true circulation of $P$. vivax in the area; we cannot exclude the possibility that the $P$. vivax-positive mosquito got infected while feeding on a non-resident as Tibati is a cross-border city with a high circulation of people.

\section{Conclusion}

We have provided a picture of the epidemiological and entomological malaria situation in Tibati, a small town in the Adamawa region of Cameroon. Malaria prevalence varied from $42 \%$ in symptomatic patients to $61 \%$ in asymptomatic individuals, and this finding highlights the high malaria endemicity in the area. Three major vectors, namely An. funestus, An. gambiae and An. coluzzii, were responsible for the transmission of the disease, with all three species contributing equally to Plasmodium transmission. Parasitological indices suggest low bednet usage and that the implementation of control interventions in the area is needed to reduce the malaria burden. We identified hotspots of disease transmission, and these sites should be the target of malaria control efforts. In addition, the presence of $P$. vivax in an An. coluzzii mosquito prompts for regular monitoring as the spread of this species could introduce further complexity into malaria epidemiology and control measures in this area.

\section{Abbreviations}

CTAB: Cetyltrimethyl ammonium bromide ; IRS: Insecticide residual spraying; LLINs: Long-lasting insecticidal nets; MINSANTE: Ministère de la Santé; PCR-RFLP: PCR-restriction fragment length polymorphism; rRNA: Ribosomal ribonucleic acid

\begin{abstract}
Acknowledgements
We are grateful to all the residents of Tibati who agreed to participate in this study and gave permission to enter their houses for mosquito collection. Our appreciation is also extended to Estelle Esssangui and Balotin Fongang for their support and cooperation during data analysis. Our sincere thanks go to Rhoel Dinglasan for his contribution in reviewing the article.
\end{abstract}

\section{Authors' contributions}

SEN and IM conceived and designed the study protocol. LBFD, EMSM, LMA, $A G B T, A N B, C M N, J C T, M M S$ and SEN carried out the field and laboratory assays. LBFD, EMSM, LMA, IM and SEN analyzed, interpreted data and wrote the paper. CEEM, LA and PAA critically reviewed the manuscript. All authors read and approved the final manuscript.

\section{Funding}

This work was carried out as part of an AUF-IRD research project granted to SEN. This research was supported by the French National Research Institute for Sustainable Development (IRD) through the JEAI-IMPALA project granted to SEN. LBFD and EMSM were supported by a doctoral fellowship from the LabEx ParaFrap.

\section{Availability of data and materials}

All data generated or analyzed during the current study are included in this published article.

\section{Declarations}

Ethics approval and consent to participate

Our study was approved by the Cameroon National Ethics Committee (N²015/04/579/CE/NERSH) and by the Delegate of Pub-

lic Health from Adamaoua region (N029/L/RA/DSP/SAGE/BPF/NGD/15;735/L/ RA/DSP/SAGE/BPF/NGD/17) and the Health Director of the Evangeli-

cal Lutheran Church ( $\left.N^{\circ} 004 / E E L C / O S E E L C / S R H / 15\right)$. All human volunteers were enrolled after providing written informed consent, either by the participants and/or by their legal guardians. Written informed consent were also provided by household owners prior to mosquito collection. Free malaria treatments with ACT were given to all Plasmodium-infected patients as recommended by the Ministry of Health (NMCP).

\section{Consent for publication}

Not applicable.

\section{Competing interests}

The authors declare that they have no competing interests.

\section{Author details}

${ }^{1}$ Service de Paludisme du Centre Pasteur Cameroun, BP 1274, Yaounde, Cameroon. ${ }^{2}$ CNRS UPR 9022, Inserm U 963, Université de Strasbourg, 2, allée Konrad Roentgen, 67084 Strasbourg Cedex, France. ${ }^{3}$ UMR MIVEGEC, IRD, CNRS, Université de Montpellier, Institut de Recherche pour le Développement, 911 avenue Agropolis, 34394 Montpellier, France. ${ }^{4}$ Université Catholique d'Afrique Centrale, Yaoundé-Campus Messa, BP 1110, Yaounde, Cameroon. ${ }^{5}$ Laboratoire de Recherche sur le Paludisme, Organisation de Coordination pour la lutte contre les Endémies en Afrique Centrale, BP 288, Yaounde, Cameroon. ${ }^{6}$ Department of Medical Entomology, Centre for Research in Infectious Diseases, Yaounde 13591, Cameroon. ${ }^{7}$ Department of Microbiology and Infectious Diseases, School of Veterinary Medicine and Sciences, University of Ngaoundere, PO Box 454, Ngaoundere, Cameroon. ${ }^{8}$ Faculté de Médecine et des Sciences Pharmaceutiques de I'Université de Douala (FMSP-UD), BP 2701 Douala, Cameroon

Received: 10 March 2021 Accepted: 23 April 2021

Published online: 08 May 2021

\section{References}

1. World Health Organization. World malaria report. Geneva: World Health Organization; 2020. https://www.who.int/publications/i/item/97892 40015791. Accessed 03 May 2021.

2. Antonio-Nkondjio C, Simard FDR, Awono-Ambene P, Chouaibou M, Tchuinkam TO, Fontenille D. Complexity of the malaria vectorial system in cameroon: contribution of secondary vectors to malaria transmission. J Med Entomol. 2006;43:7.

3. Wanji S, Tanke T, Atanga SN, Ajonina C, Nicholas T, Fontenille D. Anopheles species of the Mount Cameroon region: biting habits, feeding behaviour and entomological inoculation rates. Trop Med Int Health. 2003;8:643-9.

4. Hervy JF, Goff G, Geoffroy B, Herve JP, Manga L, Brunhes J. Les Anophèles de la région afrotropicale. CD-ROM. Paris: ORSTOM;1998.http:// www.documentation.ird.fr/hor/fdi:010014161. Accessed 03 May 2021.

5. Fontenille D, Cohuet A, Awono-Ambene PH, Antonio-Nkondjio C, Wondji C, Kengne P, et al. Systematique et biologie des Anopheles vecteurs de Plasmodium en Afrique Données récentes. Med Trop. 2003;7:247-53.

6. Fontenille D, Simard F. Unravelling complexities in human malaria transmission dynamics in Africa through a comprehensive knowledge of vector populations. Comp Immunol Microbiol Infect Dis. 2004;27:357-75. 
7. Ministère de la Santé publique du Cameroun. Plan stratégique national de lutte contre le paludisme . 2011. http://www.santetropicale.com/ rapports.asp?action=lire\&id=983\&specialite $=$. Accessed 02 May 2021.

8. PNLP. Rapport annuel du Programme de Lutte contre le Paludisme. Yaoundé Cameroun. 2020. http://onsp.minsante.cm/fr/publication/ 230/rapportannuel-2019-lutte-contre-le paludisme. Accessed 04 May 2021.

9. Etang J, Fondjo E, Chandre F, Morlais I, Brengues C, Nwane P, et al. Short report: first report of knockdown mutation in the malaria vector Anopheles gambiae from Cameroon. Am J Trop Med Hyg. 2006;3:795-7.

10. Etang J, Mbida Mbida A, Ntonga Akono P, Binyang J, Eboumbou Moukoko CE, Lehman LG, et al. Anopheles coluzzii larval habitat and insecticide resistance in the island area of Manoka. Cameroon BMC Infect Dis. 2016;16:217.

11. Nwane P, Etang J, Chouaïbou M, Toto JC, Koffi A, Mimpfoundi R, et al. Multiple insecticide resistance mechanisms in Anopheles gambiae s.l. populations from Cameroon, Central Africa. Parasites Vectors. 2013;6:41.

12. Menze BD, Riveron JM, Ibrahim SS, Irving H, Antonio-Nkondjio C, Awono-Ambene $\mathrm{PH}$, et al. Multiple insecticide resistance in the malaria vector Anopheles funestus from Northern Cameroon is mediated by metabolic resistance alongside potential target site insensitivity mutations. PLoS ONE. 2016;11:e0163261.

13. NdjemaÃ HNM, PatchokÃ S, Atangana J, Etang J. The distribution of insecticide resistance in Anopheles gambiae s.l. populations from Cameroon: an update. BMC Public Health. 2009;12:1.

14. Ekoko WE, Awono-Ambene P, Bigoga J, Mandeng S, Piameu M, Nvondo $\mathrm{N}$, et al. Patterns of anopheline feeding/resting behaviour and Plasmodium infections in North Cameroon, 2011-2014: implications for malaria control. Parasites Vectors. 2019;12:297.

15. Bamou R, Sonhafouo-Chiana N, Mavridis K, Tchuinkam T, Wondji CS, Vontas J, et al. Status of insecticide resistance and its mechanisms in Anopheles gambiae and Anopheles coluzzii populations from forest settings in South Cameroon. Genes. 2019;10:741.

16. Menard S, Morlais I, Tahar R, Sayang C, Mayengue P, Iriart X, et al. Molecular monitoring of Plasmodium falciparum drug susceptibility at the time of the introduction of artemisinin-based combination therapy in Yaoundé, Cameroon: implications for the future. Malar J. 2012;11:113.

17. Chauvin $P$, Menard S, Iriart $X$, Nsango SE, Tchioffo MT, Abate L, et al. Prevalence of Plasmodium falciparum parasites resistant to sulfadoxine/ pyrimethamine in pregnant women in Yaoundé, Cameroon: emergence of highly resistant pfdhfr/pfdhps alleles. J Antimicrob Chemother. 2015;70:2566-71.

18. Apinjoh TO, Mugri RN, Miotto O, Chi HF, Tata RB, Anchang-Kimbi JK, et al. Molecular markers for artemisinin and partner drug resistance in natural Plasmodium falciparum populations following increased insecticide treated net coverage along the slope of mount Cameroon: cross-sectional study. Infect Dis Poverty. 2017;6:136.

19. Moyeh MN, Njimoh DL, Evehe MS, Ali IM, Nji AM, Nkafu DN, et al. Effects of drug policy changes on evolution of molecular markers of Plasmodium falciparum resistance to chloroquine, amodiaquine, and sulphadoxine-pyrimethamine in the south west region of Cameroon. Malar Res Treat. 2018;2018:1-7.

20. Mbacham WF, Evehe M-SB, Netongo PM, Ateh IA, Mimche PN, Ajua A, et al. Efficacy of amodiaquine, sulphadoxine-pyrimethamine and their combination for the treatment of uncomplicated Plasmodium falciparum malaria in children in Cameroon at the time of policy change to artemisinin-based combination therapy. Malar J. 2010;9:34.

21. Anong DN, Nkuo-Akenji T, Fru-Cho J, Amambua-Ngwa A, Titanji VPK. Genetic diversity of Plasmodium falciparum in Bolifamba, on the slopes of Mount Cameroon: influence of MSP1 allelic variants on symptomatic malaria and anaemia. Ann Trop Med Parasitol. 2010;104:25-33.

22. Metoh TN, Chen J-H, Fon-Gah P, Zhou X, Moyou-Somo R, Zhou X-N. Genetic diversity of Plasmodium falciparum and genetic profile in children affected by uncomplicated malaria in Cameroon. Malar J. 2020;19:115.

23. Kwenti TE, Kwenti TDB, Njunda LA, Latz A, Tufon KA, Nkuo-Akenji T. Identification of the Plasmodium species in clinical samples from children residing in five epidemiological strata of malaria in Cameroon. Trop Med Health. 2017;45:14.

24. Moyeh MN, Ali IM, Njimoh DL, Nji AM, Netongo PM, Evehe MS, et al. Comparison of the accuracy of four malaria diagnostic methods in a high transmission setting in coastal Cameroon. J Parasitol Res. 2019;2019:1-8.

25. Songue E, Tagne C, Mbouyap P, Essomba P, Moyou R. Epidemiology of malaria in three geo-ecological zones along the chad-cameroon pipeline. Am J Epidemiol Infect Dis. 2013;13:27-33.

26. MINSANTE. Rapport d'activité 2012 du programme de lutte contre le paludisme. Yaoundé Cameroon. Ministry of health: 2013 Jul 23.

27. Ngassabenda HG, Das A. Molecular evidence of Plasmodium vivax mono and mixed malaria parasite infections in duffy-negative native Cameroonians. PLoS ONE. 2014;9:e103262.

28. Fru-Cho J, Bumah W, Safeukui I, Nkuo-Akenji T, Titanji VP, Haldar K. Molecular typing reveals substantial Plasmodium vivax infection in asymptomatic adults in a rural area of Cameroon. Malar J. 2014;13:170.

29. Russo G, Faggioni G, Paganotti GM, Djeunang Dongho GB, Pomponi A, De Santis R, et al. Molecular evidence of Plasmodium vivax infection in Duffy negative symptomatic individuals from Dschang. West Cameroon Malar J. 2017;16:74.

30. Ngassa Mbenda HG, Gouado I, Das A. An additional observation of Plasmodium vivax malaria infection in Duffy-negative individuals from Cameroon. J Infect Dev Ctries. 2016;10:682-6.

31. World Health Organization. World Malaria Report. Geneva; 2019. https://www.who.int/publications/i/item/9789241565721. Accessed 04 May 2021.

32. Anstey NM, Guerra CA, Yeung S, Price RN, Tjitra E, White NJ. Vivax Malaria: neglected and not benign. Am J Trop Med Hyg. 2007;77:79-87.

33. Sanger R, Race RR, Jack J. The duffy blood groups of New York negroes: the phenotype Fy(a-b-). Br J Haematol. 1955;1:370-4.

34. Miller LH, Mason SJ, Clyde DF, McGinniss MH. The resistance factor to Plasmodium vivax in blacks. The Duffy-blood-group genotype, FyFy. N Engl J Med. 1976;295(6):302-4.

35. Michon P, Woolley I, Wood EM, Kastens W, Zimmerman PA, Adams JH. Duiy-null promoter heterozygosity reduces DARC expression and abrogates adhesion of the P. vivax ligand required for blood-stage infection. FEBS Lett. 2001;495:111-4.

36. Rosenberg R. Plasmodium vivax in Africa: hidden in plain sight? Trends Parasitol. 2007;23:193-6.

37. Abdelraheem MH, Albsheer MMA, Mohamed HS, Amin M, Abdel Hamid MM. Transmission of Plasmodium vivax in Duffy-negative individuals in central Sudan. Trans R Soc Trop Med Hyg. 2016;110:258-60.

38. Ba H, Duffy CW, Ahouidi AD, Deh YB, Diallo MY, Tandia A, et al. Widespread distribution of Plasmodium vivax malaria in Mauritania on the interface of the Maghreb and West Africa. Malar J. 2016;15:80.

39. Golassa L, Baliraine FN, Enweji N, Erko B, Swedberg G, Aseffa A. Microscopic and molecular evidence of the presence of asymptomatic Plasmodium falciparum and Plasmodium vivax infections in an area with low, seasonal and unstable malaria transmission in Ethiopia. BMC Infect Dis. 2015;15:310.

40. Zhong D, Lo E, Wang X, Yewhalaw D, Zhou G, Atieli HE, et al. Multiplicity and molecular epidemiology of Plasmodium vivax and Plasmodium falciparum infections in East Africa. Malar J. 2018;17:185.

41. Mendes C, Dias F, Figueiredo J, Mora VG, Cano J, Sousa B, et al. Duffy negative antigen is no longer a barrier to Plasmodium vivax-molecular evidences from the African West Coast (Angola and Equatorial Guinea). PLoS Negl Trop Dis. 2011;5:e1192.

42. Karthigayan G, Plowe CV, Sá JM, Travassos MA, Thera MA, Laurens $\mathrm{MB}$, et al. Plasmodium vivax Infections over 3 Years in Duffy blood group negative Malians in Bandiagara. Mali Am J Trop Med Hyg. 2017;97:744-52.

43. Culleton R, Ndounga M, Zeyrek FY, Coban C, Casimiro PN, Takeo S, et al. Evidence for the transmission of Plasmodium vivax in the republic of the Congo West Central Africa. J Infect Dis. 2009;200:1465-9.

44. Poirier P, Doderer-Lang C, Atchade PS, Lemoine JP, de I'Isle MLC, Aboubacar A, et al. The hide and seek of Plasmodium vivax in West Africa: report from a large-scale study in Beninese asymptomatic subjects. Malar J. 2016;15:570.

45. Oboh MA, Badiane AS, Ntadom G, Ndiaye YD, Diongue K, Diallo MA, et al. Molecular identification of Plasmodium species responsible for malaria reveals Plasmodium vivax isolates in Duffy negative individuals from southwestern Nigeria. Malar J. 2018;17:439. 
46. PNDP. Plan communal de développement de la commune de Tibati. 2003. https://www.pndp.org/plan-communaux-developpement.php? dest $=$ plan\&crc $=23$. Accessed 04 May 2021

47. Tchuinkam T, Nyih-Kong B, Fopa F, Simard F, Antonio-Nkondjio C, Awono-Ambene H-P, et al. Distribution of Plasmodium falciparum gametocytes and malaria-attributable fraction of fever episodes along an altitudinal transect in Western Cameroon. Malar J. 2015;14:96.

48. Gillies MT. A Supplement to the Anophelinae of Africa South of the Sahara. 1987:146.

49. Gillies MT, De Meillon B. The Anophelinae of Africa south of the Sahara (Ethiopian Zoogeographical Region). Johannesburg: South African Institute for Medical Research. 1968.

50. Song Y, Fahs A, Feldman C, Shah S, Gu Y, Wang Y, et al. A reliable and effective method of DNA isolation from old human blood paper cards. Springerplus. 2013;2:616.

51. Collins FH, Mendez MA, Rasmussen MO, Mehaffey PC, Besansky NJ, Finnerty $\mathrm{V}$. A ribosomal RNA gene probe differentiates member species of the Anopheles gambiae complex. Am J Trop Med Hyg. 1987;37:37-41.

52. Padley D, Moody AH, Chiodini PL, Saldanha J. Use of a rapid, singleround, multiplex PCR to detect malarial parasites and identify the species present. Ann Trop Med Parasites. 2003;97:131-7.

53. Fanello C, Santolamazza F, Della TA. Simultaneous identification of species and molecular forms of the Anopheles gambiae complex by PCR-RFLP. Med Vet Entomol. 2002;16:461-4.

54. Koekemoer L, Kamau M, Hunt RH, Coetzee LL. A cocktail polymerase chain reaction assay to identify members of the Anopheles funestus (Diptera: Culicidae) group. Am J Trop Med Hyg. 2002;66:804-11.

55. Boissière A, Gimonneau G, Tchioffo MT, Abate L, Bayibeki A, AwonoAmbéné $\mathrm{PH}$, et al. Application of a qPCR assay in the investigation of susceptibility to malaria infection of the M and S Molecular Forms of An. gambiae s.s. in Cameroon. PLoS ONE. 2013;8:e54820.

56. Vo TKD, Bigot P, Gazin P, Sinou V, De Pina JJ, Huynh DC, et al. Evaluation of a real-time $P C R$ assay for malaria diagnosis in patients from Vietnam and in returned travellers. Trans R Soc Trop Med Hyg. 2007;101:422-8.

57. Mangold KA, Manson RU, Koay ESC, Stephens L, Regner M, Thomson RB, et al. Real-Time PCR for detection and identification of Plasmodium spp. J Clin Microbiol. 2005;43:2435-40.

58. Nkuo Akenji TK, Ntonifor NN, Ching JK, Kimbi HK, Ndamukong KN, Anong DN, et al. Evaluating a malaria intervention strategy using knowledge, practices and coverage surveys in rural Bolifamba, southwest Cameroon. Trans R Soc Trop Med Hyg. 2005;99:325-32.

59. Mfuh KO, Achonduh-Atijegbe OA, Bekindaka ON, Esemu LF, Mbakop CD, Gandhi K, et al. A comparison of thick-film microscopy, rapid diagnostic test, and polymerase chain reaction for accurate diagnosis of Plasmodium falciparum malaria. Malar J. 2019;18:73.

60. Afa Achonduh O, Ekollo Mbange AH, Atogho-Tiedeu B, Mbulli IA, Achinko D, Masube netongo $\mathrm{P}$, et al. Predominance of Plasmodium malariae-falciparum Co-infection by molecular speciation in Bangolan, North West Region of Cameroon. J Life Sci. 2013;7:599-606.

61. Bouyou-Akotet MK, Offouga CL, Mawili-Mboumba DP, Essola L, Madoungou B, Kombila M. Falciparum malaria as an emerging cause of fever in adults living in Gabon Central Africa. BioMed Res Int. 2014:2014:1-7.

62. Leroy EM, Nkoghe D, Ollomo B, Nze-Nkogue C, Becquart P, Grard G, et al. Concurrent Chikungunya and dengue virus infections during simultaneous outbreaks, Gabon, 2007. Emerg Infect Dis. 2009;15:591-3.

63. Ayorinde AF, Oyeyiga AM, Nosegbe NO, Folarin OA. A survey of malaria and some arboviral infections among suspected febrile patients visiting a health centre in Simawa, Ogun State. Nigeria J Infect Public Health. 2016:9:52-9.

64. Wolfe ND, Tamoufe U, Gubler DJ, Huang CY-H, Burke DS, Mpoudi-Ngole $E$, et al. Seroprevalence and distribution of flaviviridae, togaviridae, and bunyaviridae arboviral infections in rural cameroonian adults. Am J Trop Med Hyg. 2006;74:1078-83.

65. Programme National de Lutte contre le Paludisme. Rapport d'activités du programme national de lutte contre le paludisme. Yaoundé : Ministère de la Santé publique. 2015;66.

66. Topazian HM, Gumbo A, Puerto-Meredith S, Njiko R, Mwanza A, Kayange $M$, et al. Asymptomatic Plasmodium falciparum malaria prevalence among adolescents and adults in Malawi, 2015-2016. Sci Rep. 2020;10:18740.
67. Pulford J, Hetzel MW, Bryant M, Siba PM, Mueller I. Reported reasons for not using a mosquito net when one is available: a review of the published literature. Malar J. 2011;10:83.

68. Ndo C, Menze-Djantio B, Antonio-Nkondjio C. Awareness, attitudes and prevention of malaria in the cities of Douala and Yaoundé (Cameroon). Parasites Vectors. 2011;4:181.

69. Bousema T, Okell L, Felger I, Drakeley C. Asymptomatic malaria infections: detectability, transmissibility and public health relevance. Nat Rev Microbiol. 2014;12:833-40.

70. Lindblade KA, Steinhardt L, Samuels A, Kachur SP, Slutsker L. The silent threat: asymptomatic parasitemia and malaria transmission. Expert Rev Anti Infect Ther. 2013;17:623-39.

71. Morlais I, Nsango SE, Toussile W, Abate L, Annan Z, Tchioffo MT, et al. Plasmodium falciparum mating patterns and mosquito infectivity of natural isolates of gametocytes. PLoS ONE. 2015;10:e0123777.

72. Mmbando BP, Lusingu JP, Vestergaard LS, Lemnge MM, Theander TG, Scheike TH. Parasite threshold associated with clinical malaria in areas of different transmission intensities in north eastern Tanzania. BMC Med Res Methodol. 2009;9:12.

73. Smith T, Schellenberg JA, Hayes R. Attributable fraction estimates and case definitions for malaria in endemic areas. Stat Med. 1994;13(22):2345-58

74. Greenwood BM, Bradley AK, Greenwood AM, Byass P, Jammeh K, Marsh K, et al. Mortality and morbidity from malaria among children in a rural area of The Gambia, West Africa. Trans R Soc Trop Med Hyg. 1987;81:478-86.

75. Mogeni P. Effect of transmission intensity on hotspots and micro-epidemiology of malaria in sub-Saharan Africa. BMC Med. 2017;15:11.

76. Stresman GH, Mwesigwa J, Achan J, Giorgi E, Worwui A, Jawara M, et al. Do hotspots fuel malaria transmission: a village-scale spatio-temporal analysis of a 2-year cohort study in The Gambia. BMC Med. 2018;16:160.

77. Bousema T, Drakeley C, Gesase S, Hashim R, Magesa S, Mosha F, et al. Identification of hot spots of malaria transmission for targeted malaria control. J Infect Dis. 2010;201:1764-74.

78. Bousema T, Stresman G, Baidjoe AY, Bradley J, Knight P, Stone W, et al. The impact of hotspot-targeted interventions on malaria transmission in Rachuonyo South District in the Western Kenyan Highlands: a cluster-randomized controlled trial. Rogerson SJ, editor. PLOS Med. 2016;13:e1001993.

79. Ngassa Mbenda HG, Das A. Analysis of genetic diversity in the chloroquine-resistant gene Pfcrt in field Plasmodium falciparum isolates from five regions of the southern Cameroon. Infect Genet Evol. 2016;44:450-8

80. Sandeu MM, Abate L, Tchioffo MT, Bayibéki AN, Awono-Ambéné PH, Nsango SE, et al. Impact of exposure to mosquito transmission-blocking antibodies on Plasmodium falciparum population genetic structure. Infect Genet Evol. 2016:45:138-44.

81. Gautret P, Legros F, Koulmann P, Rodier MH. Imported Plasmodium vivax malaria in France: geographical origin and report of an atypical case acquired in Central or Western Africa. Acta Trop. 2001;5:177-81.

82. Mangoni ED, Severini C, Menegon M, Romi R, Ruggiero G, Majori G. Case report: an unusual late relapse of Plasmodium vivax malaria. Am J Trop Med Hyg. 2003;2:159-60.

83. Twohig KA, Pfeffer DA, Baird JK, Price RN, Zimmerman PA, Hay SI, et al. Growing evidence of Plasmodium vivax across malaria-endemic Africa. PLoS Negl Trop Dis. 2019;13:e0007140.

84. Tabue RN, Awono-Ambene P, Etang J, Atangana J, Antonio-Nkondjio C, Toto JC, et al. Role of Anopheles (Cellia) rufipes (Gough, 1910) and other local anophelines in human malaria transmission in the northern savannah of Cameroon: a cross-sectional survey. Parasites Vectors. 2017;10:22

85. Ayala D, Costantini C, Ose K, Kamdem GC, Antonio-Nkondjio C, Agbor J-P, et al. Habitat suitability and ecological niche profile of major malaria vectors in Cameroon. Malar J. 2009;8:307.

86. Bigoga JD, Manga L, Titanji VP, Coetzee M, Leke RG. Malaria vectors and transmission dynamics in coastal south-western Cameroon. Malar J. 2007;6:5.

87. Menze BD, Wondji MJ, Tchapga W, Tchoupo M, Riveron JM, Wondji CS. Bionomics and insecticides resistance profiling of malaria vectors at a selected site for experimental hut trials in central Cameroon. Malar J. 2018;17:317. 
88. Antonio-Nkondjio C, Sonhafouo-Chiana N, Ngadjeu CS, DoumbeBelisse P, Talipouo A, Djamouko-Djonkam L, et al. Review of the evolution of insecticide resistance in main malaria vectors in Cameroon from 1990 to 2017. Parasites Vectors. 2017;10:472.

89. Tchouakui M, Fossog BT, Ngannang BV, Djonabaye D, Tchapga W, Njiokou F, et al. Investigation of the influence of a glutathione S-transferase metabolic resistance to pyrethroids/DDT on mating competitiveness in males of the African malaria vector Anopheles funestus. Wellcome Open Res. 2019;4:4-13.

90. Cohuet A, Dia I, Simard F, Raymond M, Rousset F, Antonio-Nkondjio C, et al. Gene flow between chromosomal forms of the malaria vector Anopheles funestus in Cameroon, Central Africa, and its relevance in malaria fighting. Genetics. 2005;169:301-11.

91. Antonio-Nkondjio C, Fossog BT, Ndo C, Djantio BM, Togouet SZ, Awono-Ambene $\mathrm{P}$, et al. Anopheles gambiae distribution and insecticide resistance in the cities of Douala and Yaoundé (Cameroon): influence of urban agriculture and pollution. Malar J. 2011;10:154.

92. Tia E, Chouaibou M, Gbalégba CNG, Boby AMO, Koné M, Kadjo AK Distribution des espèces et de la fréquence du gène $K d r$ chez les populations d'Anopheles gambiaes.s. et d'Anopheles coluzzii dans cinq sites agricoles de la Côte d'Ivoire. Bull Soc Pathol Exot. 2017;110:130-4.

93. Kamdem C, Tene Fossog B, Simard F, Etouna J, Ndo C, Kengne P, et al. Anthropogenic habitat disturbance and ecological divergence between incipient species of the malaria mosquito Anopheles gambiae. PLOS ONE. 2012;7:e39453.

94. Simard F, Ayala D, Kamdem G, Pombi M, Etouna J, Ose K, et al. Ecological niche partitioning between Anopheles gambiae molecular forms in Cameroon: the ecological side of speciation. BMC Ecol. 2009;9:17.

95. Tene Fossog B, Kopya E, Ndo C, Menze-Djantio B, Costantini C, Njiokou $F$, et al. Water quality and Anopheles gambiae larval tolerance to pyrethroids in the cities of douala and yaoundé (Cameroon). J Trop Med. 2012;2012:1-10.
96. Minsanté. Xlième Journée mondiale de lutte contre le paludisme "prêt à vaincre le paludisme" Nous sommes la génération qui peut éliminer lepaludisme. Cameroon tribune. 2018. https://www.cameroon-tribune. $\mathrm{cm} /$ article.html/159/fr.html/extreme-nord-baisse-du-taux-de-morta lite-liee-aupaludisme.Accessed 03 May 2021.

97. Lekweiry K, Salem M, Basco LK, Briolant S, Hafid J, Boukhary A. Malaria in Mauritania: retrospective and prospective overview. Malar J. 2015;14:100.

98. Zohdy S, Derfus K, Headrick EG, Andrianjafy MT, Wright PC, Gillespie TR. Small-scale land-use variability affects Anopheles spp. distribution and concomitant Plasmodium infection in humans and mosquito vectors in southeastern Madagascar. Malar J. 2016;15:114.

99. Rakotoarivony I, Coulanges P, Coluzzii M, Campbell GH, Fontenille D, Lepers JP. Malaria transmission and vector biology in manarintsoa, high plateaux of madagascar. Am J Trop Med Hyg. 1990;43:107-15.

100. Animut A, Balkew M, Gebre-Michael T, Lindtjørn B. Blood meal sources and entomological inoculation rates of anophelines along a highland altitudinal transect in south-central Ethiopia. Malar J. 2013;12:76.

101. Robert V, Le Goff G, Andrianaivolambo L, Randimby FM, Domarle O, Randrianarivelojosia $\mathrm{M}$, et al. Moderate transmission but high prevalence of malaria in Madagascar. Int J Parasitol. 2006;36:1273-81.

102. Amon J, Wirtz RA, Koros J, Ryan JR, Mtalib R, Luckhart S, et al. Evidence for transmission of Plasmodium vivax among a duffy antigen negative population in western Kenya. Am J Trop Med Hyg. 2006;75:575-81.

\section{Publisher's Note}

Springer Nature remains neutral with regard to jurisdictional claims in published maps and institutional affiliations.
Ready to submit your research? Choose BMC and benefit from:

- fast, convenient online submission

- thorough peer review by experienced researchers in your field

- rapid publication on acceptance

- support for research data, including large and complex data types

- gold Open Access which fosters wider collaboration and increased citations

- maximum visibility for your research: over $100 \mathrm{M}$ website views per year

At BMC, research is always in progress.

Learn more biomedcentral.com/submissions 